ATAPS for children

\title{
Improving access to primary mental health care for Australian children
}

\section{Abstract}

Objective: This study examines the uptake by children aged predominantly 0-11 years of an Australian primary mental health service - the Access to Allied Psychological Services (ATAPS) program - which began in 2001. In particular, it considers access to, and use of, the child component of ATAPS, the Child Mental Health Service (CMHS), introduced in 2010.

Method: Using routinely collected program data from a national minimum dataset and regional population data, we conducted descriptive and regression analysis to examine program uptake, predictors of service reach, and consumer- and treatment-based characteristics of service.

Results: Between 2003 and 2013, 18,631 referrals for children were made and 75,178 sessions were scheduled via ATAPS, over $50 \%$ of which were via the CMHS in its first three years of operation. The rate of referrals for children to the CMHS was associated with the rate of ATAPS referrals for consumers aged $12+$ years.

Conclusions: The CMHS has increased services provided within the ATAPS program for children with emotional and behavioural issues and their families, and is potentially filling a service gap in the area of prevention and early intervention for children who have significant levels of need but are unable to access other mental health services. Our findings are policy-relevant for other developed countries with a similar primary mental health care system that are considering means of improving service access by children. 


\section{ATAPS for children}

Key words: child mental health, children's health services, mental health service, primary health care 


\section{ATAPS for children}

\section{Introduction}

Childhood, defined in this paper as ages 0 to 11 years inclusive, is a crucial developmental period. Childhood emotional and behavioural problems are an important public health concern in Australia and internationally. Early identification of children at risk of emotional and behavioural problems creates opportunities for intervention that can help to avert or ameliorate problems in later life. Access to services tailored to children that focus on early identification and treatment may mitigate the persistence or severity of primary disorders and prevent comorbid disorders (Kessler et al., 2007). Primary mental health services have an important role to play in recognising vulnerable children and offering appropriate care and support. This paper describes utilisation by children of an Australian primary mental health program, which introduced services specifically tailored for children.

\section{Child emotional and behavioural health in Australia}

The most recent Australian survey of child and adolescent mental health, conducted in 2013-14, recruited 6,310 parents and carers of children aged 4-17 years and 2,967 children aged 11-17 years and found that $14 \%$ of children and adolescents had a mental disorder in the previous year, which was associated with a substantial number of days absent from school (Lawrence et al., 2015). Furthermore, the survey found that $56 \%$ of $4-17$ year olds with mental disorders had accessed mental health services (e.g., family doctors, psychologists, paediatricians and counsellors/family therapists) in the year preceding the survey (Johnson et al., 2016), which is an improvement on the rate of service use reported in 1997; 25\% in the preceding six months (Sawyer et al., 2000). 


\section{ATAPS for children}

\section{The Access to Allied Psychological Services program}

The Access to Allied Psychological Services (ATAPS) program has been delivering primary mental health services to the Australian community since 2001, with an evolving emphasis on hard-to-reach groups. ATAPS was the first program to provide community access to government-funded psychological treatment of common mental disorders in Australia. ATAPS was implemented through Divisions of General Practice ('Divisions'), which transitioned to Medicare Locals in 2011-12 (in a series of funding rounds or 'tranches') to support general practitioners (GPs; 'family physicians') and mental health professionals to collaborate to provide optimal primary mental health care. ATAPS enabled GPs to refer consumers of any age with high prevalence disorders (e.g., depression and anxiety) to mental health professionals for up to 12 (or 18 in exceptional circumstances) individual sessions, with the option for an additional 12 group sessions of evidence-based mental health care (predominantly Cognitive Behavioural Therapy, or CBT) (Hickie and Groom, 2002). Review by the referring GP was mandatory after each block of six sessions and/or the final session.

During the life of ATAPS, several ATAPS initiatives were introduced that focussed on particular at-risk populations, including women with perinatal depression; people at risk of suicide or self-harm or who were identified as being at high risk of suicide (King et al., 2013); people experiencing, or at high risk of homelessness; people affected by extreme climatic events, such as bushfires (Bassilios et al., 2012b) or floods (Reifels et al., 2015); people in remote locations (Morley et al., 2007); and children with, or are at risk of developing, a mental, childhood behavioural or emotional disorder. Some initiatives have also used alternative modalities to face to face service delivery, such as telephone- or web-based CBT (Bassilios et al., 2012a). These additional initiatives aimed to enhance capacity to address the needs of these groups and provide increased service flexibility (Reifels et al., 2013). The original ATAPS arrangements came to be known as the 'Tier 1' initiative, and the sub-programs as the 


\section{ATAPS for children}

'Tier 2' initiatives (Australian Government Department of Health and Ageing, 2012c). These initiatives were introduced at different times since 2008; some of them were mandatory, while others were elective for Medicare Locals.

From July 2016, government-funded primary care psychological treatment for people of all ages will be locally commissioned by 30 Primary Health Networks (which replaced Medicare Locals in July 2015). This reform will be supported by a flexible funding pool for mental health and suicide prevention services that enables targeting services within a stepped care approach according to local population mental health needs (Department of Health, 2014). This policy change has resulted from a major review of national mental health services completed in 2014 (National Mental Health Commission, 2014) and the Department of Health response to this review (Australian Government Department of Health, 2015).

\section{The ATAPS Child Mental Health Service}

The ATAPS Child Mental Health Service (CMHS) was introduced in July 2010 and was primarily aimed at children aged 11 years or under with, or who are at risk of developing, a mental, behavioural or emotional disorder. Its objectives were to: (1) increase ATAPS service delivery provided for children with mental health and behavioural issues and their families; (2) provide a high quality standard of service that is clinically appropriate for children, including the provision of education and training resources to support service delivery; and (3) establish and maintain linkages and support networks with mental health service providers and community workers, including school counsellors. In exceptional circumstances, children aged between 12 and 15 years, inclusive, could also receive services via the $\mathrm{CMHS}$. 


\section{ATAPS for children}

The CMHS offered ATAPS providers with greater flexibility to deliver appropriate treatment and support than Tier 1 ATAPS. Specifically, a diagnosis was not mandatory and referrals could be made by school counsellors, school principals and directors of early childhood services (as well as by GPs, psychiatrists, ATAPS mental health professionals and paediatricians who could refer across the whole of ATAPS). Up to the first three sessions could be used for the purpose of assessment. Services could include family interventions based on behaviour therapy, parent training in behaviour management, attachment intervention, parent-child interaction therapy and liaison with key providers in the children's other environments, such as schools. Finally, sessions could involve parents or the whole family with or without the child present (whereas in other ATAPS initiatives, parents could not attend sessions related to the child unless the child was present).

ATAPS funding was significantly increased in the 2011-12 Australian Federal Budget to enhance capacity to provide services to an additional 50,000 children and their families over five years (Australian Government Department of Health and Ageing, 2012a). Consequently, implementation of the CMHS became mandatory for all Medicare Locals in July 2012. In order to assist Medicare Locals with the quality implementation of the CMHS, the Department of Health provided them with funding for additional supports and resources (Australian Government Department of Health and Ageing, 2012a). For example, Medicare Locals were able to engage staff to a maximum of one fulltime equivalent in order to fulfil the function of CMHS Coordination and Liaison; that is, to develop and maintain effective linkages with service providers and community groups to meet the objectives of the CMHS. Medicare Locals were also granted three months to enhance and expand existing services in order to more appropriately meet the needs of children and their families. This allowed for the establishment of formal linkages and referral pathways, engagement or up-skilling of mental health professionals, and development and promotion of support structures. Additionally, the Australian Psychological Society was funded to develop online training for mental health 


\section{ATAPS for children}

professionals who required up-skilling to meet the necessary skills and competencies to deliver the CMHS.

This is the first in-depth study of the CMHS and aims to determine: (1) whether there has been an increase in services provided to children via ATAPS (from July 2003 to June 2013) since the introduction of the CMHS (in July 2010); (2) which Medicare Local regional factors are associated with differential uptake of the CMHS; (3) the socio-demographic characteristics of children accessing the CMHS; and (4) the nature of the treatment delivered within the CMHS. 


\section{ATAPS for children}

\section{Method}

\section{Data sources}

\section{Minimum dataset}

We extracted the following data from a purpose-designed minimum dataset: the number of referrals and sessions delivered to children aged 0-11 years (via the CMHS and ATAPS overall) and the referral and treatment characteristics for those referred to the CMHS. The minimum dataset captures de-identified, consumer-level and session-level information, which are collected by providers and entered by Medicare Local staff or providers as required by Medicare Locals' funding agreement with the Department of Health. Data for the period from 1 July 2003 to 30 June 2013 were downloaded on 28 October 2013.

\section{Medicare Local-level population data}

Medicare Locals were established in three tranches: 19 in Tranche 1 from 1 July 2011, 18 in Tranche 2 from 1 January 2012 and 24 in Tranche 3 from 1 July 2012. The Department of Health provided us with 2009 Australian Bureau of Statistics Estimated Resident Populations for each Medicare Local (including total population and population aged 0 to 11 years), based on 2006 Australian Census data. The data were disaggregated by the Socio-Economic Indexes for Areas (SEIFA) Index for Relative Socio-Economic Disadvantage (IRSED, in quintiles) (Australian Bureau of Statistics, 2008) and the Australian Standard Geographical Classification Remoteness Area (ASGC-RA) classifications (major cities, inner regional, outer regional, remote and very remote) (Australian Bureau of Statistics, 2013), also derived from the 2006 census data. Together with the tranche of each Medicare Local, these data were used to explore factors that might contribute to levels of service delivery by Medicare Locals. 


\section{ATAPS for children}

\section{Data analyses}

\section{Descriptive analyses}

Using SPSS Version 21, simple frequencies and percentages were calculated from the minimum dataset data to report on trends in uptake of the CMHS specifically and on uptake of other ATAPS initiatives by children; socio-demographic and clinical characteristics of consumers of the CMHS; and the types of services delivered within the CMHS.

\section{Regression analysis}

We performed standard multiple regression analysis to identify the factors associated with differential service reach to children by Medicare Locals via the CMHS. Our dependent variable was defined as the number of unique children referred to the CMHS (noting that an individual child could have multiple referrals) divided by the total number of children in the population per year in each Medicare Local. We express this as a rate per 100 per year.

We used the Medicare Local as the unit of analysis, meaning that all of our predictor variables were measured at the Medicare Local-level. Our independent (predictor) variables were: the proportion of children in the population in the two most disadvantaged quintiles in each Medicare Local; the proportion of children residing in outer regional, remote and very remote locations in each Medicare Local; the referral rate for consumers aged $12+$ years; and the tranche in which each Medicare Local was funded. The referral rate for consumers aged $12+$ years was defined as the number of people referred to ATAPS aged $12+$ years divided by the total number of people in the population aged $12+$ years per year in each Medicare Local (expressed as a rate per 100 per year). These predictors were 


\section{ATAPS for children}

considered relevant as the rate of child referrals could be influenced by socio-economic status, geographic location, the overall rate of referrals to a given Medicare Local and duration since establishment of each Medicare Local. 


\section{ATAPS for children}

\section{Results}

\section{Uptake of ATAPS by children}

Figure 1 shows the number of referrals for children made to the CMHS and all other ATAPS initiatives between July 2003 and June 2013, by financial year. Overall, 18,631 referrals for children were received via all ATAPS initiatives during this 10 -year period, more than half $(n=9,586$ or $51.5 \%)$ of which were received via the CMHS in its first three years of operation. Since its introduction, the proportion of children referred to the CMHS as compared with other initiatives has steadily increased from $46.5 \%$ in $2010-2011$ to $84.3 \%$ in 2012-2013. Moreover, since the CMHS was introduced, the overall number of children referred to ATAPS in general almost tripled, from 2,295 in 2010-2011 to 6,797 in 2012-2013. Correspondingly, the proportion of referrals for children to all ATAPS initiatives (4.8\% overall, not shown) steadily increased from $0.9 \%$ in $2003-2004$ to $3.7 \%$ in $2009-2010$ (prior to the introduction of the CMHS) and 9.7\% in 2012-2013.

Overall, 15,018 referrals (80.6\%) for children to all ATAPS initiatives and 7,850 referrals (81.9\%) for children to the CMHS resulted in one or more sessions scheduled by a mental health professional. Overall, 75,178 sessions were offered to children in the 10 -year analysis period, $51.1 \%(n=38,420)$ of which were offered via the CMHS in its first three years of operation. In total, 4,408 sessions (5.9\%) offered to children were unattended, 2,566 of which were unattended in the CMHS. The average number of sessions per referral offered via the CMHS was 5.4 (including unattended sessions) and 4.9 (attended sessions only). Consistent with the referral pattern, since its introduction, the proportion of ATAPS sessions delivered to children via the CMHS steadily increased from $41.4 \%$ in 2010-2011 to $81.9 \%$ in 2012-2013. Furthermore, since the introduction of the CMHS, the overall number of sessions delivered to children more than tripled from 8,773 in $2010-2011$ to 28,954 in 


\section{ATAPS for children}

2012-2013. Overall, sessions delivered to children comprised $4.7 \%$ of all sessions delivered via any ATAPS initiative in the 10 -year analysis period; this proportion steadily increased from $0.6 \%$ in 2003 2004 to $3.6 \%$ in $2009-2010$ (prior to the introduction of the CMHS) and $8.9 \%$ in $2012-2013$.

\section{Predictors of referrals to the CMHS}

Table 1 shows the correlations between the independent variables and rate of children referred to the CMHS as a proportion of the population of children in each Medicare Local (the dependent variable) and the regression coefficients (B) for the independent (predictor) variables. As shown in Table 1, the combination of all four predictor variables in the regression equation accounted for a significant percentage of variance $(19 \%)$ in the rate of referral of children to the CMHS $(R=.44$, $F(4,56)=3.29 p=.02)$. However, only the rate of ATAPS referrals for consumers aged $12+$ years made a significant independent contribution to the prediction of the rate of referral of children to the CMHS. These findings indicate that the rate at which children are referred to the CMHS is associated with the rate of referrals aged $12+$ years to ATAPS; for every $1 \%$ increase in the rate of referrals aged $12+$ years to ATAPS in a Medicare Local, the rate of children referred to the CMHS increased by $0.06 \%$.

\section{Table 1}




\section{ATAPS for children}

\section{Demographic and clinical characteristics of CMHS consumers}

Table 2 summarises the key characteristics of the 9,586 referrals (representing 9,090 individuals) to the CMHS, and where available comparable percentage breakdowns for all Australian children using 2006 Census data (Australian Bureau of Statistics, 2007) to be consistent with the data source used for Medicare Local characteristics. Proportionally, the CMHS seems to at least marginally target difficult to reach sub-populations of children, such as males, Indigenous people, and those residing in regional locations; however, children residing in remote areas appear to be under-serviced and the level of access by children from Culturally and Linguistically Diverse backgrounds is unclear given that language spoken at home data were missing for $13 \%$ of $\mathrm{CMHS}$ consumers. The mean age of children referred to the CMHS was 9.5 years. A small proportion of referrals to the CMHS (6.8\%) appear to be for children aged over 15 years, although this could reflect errors in data entry. Of all referrals for children to the CMHS, over $38 \%$ were aged $5-9$ years, slightly more were male than female $(52.4 \%$ vs. 46.4\%), 4.6\% were Aboriginal and/or Torres Strait Islanders, 86.2\% spoke English at home, $60 \%$ were reported to be from a family with a low income (based on the referrer's judgement). Referred children mainly resided in major cities (56.2\%), or regional locations (38.1\%).

The most commonly reported diagnoses were anxiety disorders (33.9\%), depression (18.0\%) and 'other' diagnoses (31.7\%). The high proportion of 'other' diagnoses is explained by the relatively recent introduction of child-specific diagnoses (i.e., enuresis, conduct disorder, dissociative disorder, eating disorders, hyperkinetic disorder, neurasthenia, sexual disorders and sleep problems) to the minimum dataset in May 2013. Prior to this, the diagnosis of children with these disorders would have been classified as 'other' diagnosis in the minimum dataset. Three per cent of children were classified as not having a formal diagnosis, which is consistent with the CMHS Operational Guidelines deeming children who are 'at risk' of developing a mental disorder as eligible for the service 


\section{ATAPS for children}

(Australian Government Department of Health and Ageing, 2012b). Of all children referred to the CMHS, close to half had not previously accessed psychiatric care (47.1\%).

\section{Table 2}

\section{CMHS treatment characteristics}

The majority of sessions ( $n=35,854$ or $93.3 \%$ ) scheduled via the CMHS were attended by consumers or their families. These sessions were delivered to either the child alone (37.8\%), one or more parents or family members without the child present (3.0\%), or individuals (either child or parent or other family member; $35.0 \%)$. Around $16 \%$ of sessions were delivered with both the child and one or more parents or family members present. Finally, $4.7 \%$ of sessions were delivered in a group format, meaning the child and/or parents or family members received psychological therapy along with a group of other children and/or parents or family members. Information about who attended the session was missing for $3.9 \%$ of sessions. Most sessions were of $46-60$ minutes duration ( $88.4 \%)$, $8.6 \%$ were over 60 minutes and $2.2 \%$ were less than 46 minutes duration. The vast majority of attended sessions (93.5\%) were delivered face to face, with $0.7 \%$ of sessions delivered via the telephone. Web-based and videoconferencing sessions were very rare $(n=28)$. Only $5.9 \%$ or 2,118 of 35,854 sessions incurred a co-payment over the life of the CMHS. The mean co-payment amount (for sessions incurring a co-payment) across all years was $\$ 21.97(\mathrm{SD}=\$ 24.28)$. The mean cost per session (for all sessions delivered) amounts to $\$ 2.86(S D=\$ 11.47)$.

Table 2 shows the intervention types delivered in CMHS sessions. The most common interventions were CBT-behavioural (39.6\%) and CBT-cognitive (39.1\%) interventions, accounting for 14,211 and 


\section{ATAPS for children}

14,016 sessions, respectively. This was followed by psycho-education (26.3\%), CBT-skills training (24.8\%), diagnostic assessment (21.9\%) and interpersonal therapy (19.6\%). Around 56\% (or 4,419 of $7,850)$ of referrals who took up the service received sessions that were classified as involving diagnostic assessment (not shown). Of the 4,419 CMHS referrals (or 7,848 CMHS sessions) involving diagnostic assessment, the majority received one $(60.3 \%)$, two $(23.0 \%)$ or three $(8.3 \%)$ separate assessment sessions. 


\section{ATAPS for children}

\section{Discussion}

This study examined mental health service delivery to children via the CMHS. Our first aim was to determine whether there had been an increase in services provided to children via ATAPS since the introduction of the CMHS. We have shown that there was a steady increase in the number of children (and their corresponding sessions) over the life of ATAPS, which became more pronounced after the introduction of the CMHS, with the overall number of children referred to ATAPS nearly tripling from 2,295 in 2010-2011 to 6,797 in 2012-2013. Although it is unlikely that this level of service use would have existed outside of ATAPS, it is possible that a minority of families (those less socio-economically disadvantaged) may have purchased similar services prior to its introduction. Furthermore, although uptake of ATAPS by children/families is substantial, it should be contextualised in terms of other available mental health care pathways available in Australia - specialist mental health services and ambulatory or residential mental health-related care provided by general health services. For example, Medicare-subsidised mental health-related services (provided by psychologists and other allied health professionals) were received by over 104,000 children aged 14 years and under in 2012-2013 (Australian Institute of Health and Welfare, 2014). Despite its relatively smaller reach, because of its unique service provision characteristics, the CMHS is complementary in that it has the potential to reach consumers with a different profile.

Our second aim was to explore Medicare Local regional factors associated with differential uptake of the CMHS. Of the factors examined in relation to their impact on uptake by children, only the rate of referrals aged $12+$ years was significantly associated with levels of service delivery to children. This finding could suggest that in regions where referrers are cognisant of and referring consumers to ATAPS, they are likely to refer consumers irrespective of their age. This effect may have been related to the extent of Medicare Locals' 'presence' in the community, promotion of ATAPS and its CMHS, 


\section{ATAPS for children}

partnerships with health and other stakeholder agencies, and other factors impacting on their overall performance within the healthcare landscape. The fact that socio-economic position, geographic spread and date of establishment of Medicare Locals were not significantly associated with levels of service delivery to children could suggest that, like the overall ATAPS program (Bassilios et al., 2010), the CMHS is providing relatively equal access to services, which is at least in part attributable to the service being generally available for free. By contrast, although Australia's larger scale Medicaresubsidised Better Access program has a far greater reach, around three-quarters of its total consumers are from major cities or other major metropolitan centres and socio-economically disadvantaged people are less likely than socio-economically advantaged people to utilise Better Access (Harris et al., 2010).

The rate of uptake of services (acceptance of referral) by children and their families was very similar to the overall uptake rate of ATAPS by consumers of all ages ( $81 \%$ vs $79 \%$ referrals resulting in sessions) (Bassilios et al., 2013) and to that observed in other studies. For example, one study of 363 patients reported that $48 \%$ of people referred to the UK Improving Access to Psychological Therapy (IAPT) program did not take up the service, despite being referred by their GP (Di Bona et al., 2014). Potential reasons for not taking up the CMHS include communication between GPs and parents, parent perception that CBT treatment is either not needed or will not be useful (Morgan et al., 2014), stigma associated with mental health problems and receiving treatment (Clement et al., 2014), access barriers (travel, cost, waiting time for services), family discord or crises (Smith et al., 2013), and actual or hoped natural resolution of symptoms.

Our third and fourth aims were to describe the socio-demographic characteristics of children accessing the $\mathrm{CMHS}$ and the nature of the treatment delivered, respectively. Some consumer and service characteristics are noteworthy. For example, slightly more males than females were referred ( $52 \%$ vs $46 \%$ ), which is desirable given that the prevalence of mental disorders is slightly higher in boys than girls (Sawyer et al., 2000). The fact that Indigenous children accounted for $4.6 \%$ of referrals is 


\section{ATAPS for children}

promising given that $4.2 \%$ of Australia's children and young people are Indigenous (Australian Bureau of Statistics, 2011). The majority of children/families were considered to receive a low income, which is consistent with the aim of the overall ATAPS program of targeting people who are hard-to-reach.

The CMHS flexibility for parents to attend sessions with or without their children is favoured by stakeholders in terms of the therapeutic benefit conferred to the child and family (Bassilios et al., 2014). This valued option is not available via other ATAPS initiatives, nor via Better Access (Pirkis et al., 2011). CBT-skills training and diagnostic assessment were more commonly delivered in the CMHS than in overall ATAPS ( $25 \%$ vs. $18 \%$ and $22 \%$ vs. $16 \%$, respectively). Variations in the interventions delivered via the CMHS might be attributable to some of the flexibilities of the CMHS permitted by the guidelines, such as, the allowance of up to three sessions per referral to be used for assessment and the possibility of parents attending sessions with or without the child. For example, the latter might account for the elevated use of CBT-skills training within the CMHS. However, it should be noted that the fidelity of interventions delivered via ATAPS is not currently assessed.

\section{Limitations}

Findings should be interpreted in the context of several limitations. Data from the minimum dataset is prone to: missing data in some non-mandatory variables; the addition of new data fields to reflect changes to program guidelines and actual practice; lags in data entry with some Medicare Locals or providers not entering session data until all sessions for a given consumer are complete. The average number of sessions per consumer may be underestimated, as Medicare Locals differ in their ability to identify re-referrals for the same consumer which means they may inadvertently assign a given consumer both a new patient identification number and referral number after the initial six sessions. The population characteristics data used in the regression analyses were limited in type and number and may have masked heterogeneity within the Medicare Local areas. Furthermore, these data did not take into account the prevalence of mental disorders in children in the population or the availability 


\section{ATAPS for children}

and utilisation of other (non-ATAPS) mental health services, in each Medicare Local region, the data for which were not available at the time of our analyses. Therefore, the extent to which the CMHS is meeting demand for children's mental health services could not be determined. Although all Medicare Locals were implementing the CMHS at the time of our analysis, they were in varied stages of implementation, which was not included as a predictor. Future research could investigate other factors potentially impacting on access to primary care psychological treatment in the new Primary Health Network regions with a view to developing strategies to improve reach to consumers of all ages.

Finally, sufficient outcome data for statistical analysis were not yet available, which may be attributable to factors ranging from clinician willingness to administer and report outcome data (Cesare, 2013) to consumer dropout either due to symptom improvement or disengagement from therapy. Improved recording of outcome measure scores and/or reasons for termination as standard would assist in better understanding the outcomes of the CMHS. Strategies to improve the proportion of outcome data could include more regular monitoring of outcomes (Wolpert et al., 2012) than at the first, sixth and/or final session and promoting the clinical utility (Cesare, 2013) of outcome measurement to providers (e.g., informing clinical work, monitoring programs, modelling data to produce intervention norms) (Wolpert et al., 2012).

\section{Conclusions}

The CMHS was successful in increasing services provided within the ATAPS program for children with emotional and behavioural issues and their families, and led to rapid uptake. This finding suggests that the CMHS is potentially filling a service gap in the area of prevention and early intervention for children who are unable to access other and larger-scale mental health services. There are indications that levels of service delivery to children are unrelated to socio-economic position, residence in regional and remote locations and date of establishment of Medicare Locals. It will be interesting to see what impact the imminent changes in Australia's primary mental health care landscape have on service 


\section{ATAPS for children}

reach to children. Our findings are policy-relevant for other developed countries with a similar primary mental health care system that are considering means of improving service access by children. Future research could examine outcome data for children receiving primary mental health care, including reasons for termination, in order to determine the impact on symptoms and functioning.

\section{Acknowledgements}

Strategic Data Pty Ltd developed and maintains the minimum dataset from which the data for this study were extracted. An early version of this paper was presented at the 49th Australian Psychological Society Conference in Hobart, Australia, on 30 September 2014.

\section{Funding acknowledgement}

This work was supported through funding from the Australian Government Department of Health.

\section{Declaration of conflicting interests}

None to declare. 


\section{ATAPS for children}

\section{References}

Australian Bureau of Statistics. (2007) 2006 Census of Population and Housing. Canberra: Commonwealth of Australia.

Australian Bureau of Statistics. (2008) Information Paper: An Introduction to Socio-Economic indexes for Areas (SEIFA), 2006 (Cat No. 2039.0). Canberra: Australian Bureau of Statistics.

Australian Bureau of Statistics. (2011) 4725.0 - Aboriginal and Torres Strait Islander Wellbeing: A focus on children and youth, Apr 2011 Canberra: Austraian Bureau of Statistics.

Australian Bureau of Statistics. (2013) Australian Standard Geographical Classification (ASGC) Correspondences. Available at: http://www.abs.gov.au/websitedbs/d3310114.nsf/home/correspondences.

Australian Government Department of Health. (2015) Australian Government response to Contributing Lives, Thriving Communities - Review of mental health programmes and services. Canberra, Australia.

Australian Government Department of Health and Ageing. (2012a) Draft Operational Guidelines for the Access to Allied Psychological Services (ATAPS) program, April 2012. Canberra: Department of Health and Ageing.

Australian Government Department of Health and Ageing. (2012b) Draft Operational Guidelines for the Access to Allied Psychological Services (ATAPS) program, Child Mental Health Service (CMHS), April 2012. Canberra: Department of Health and Ageing.

Australian Government Department of Health and Ageing. (2012c) Operational Guidelines for the Access to Allied Psychologial Services Initiative. Canberra: Mental Health Services Branch, Mental Health and Drug Treatment Division.

Australian Institute of Health and Welfare. (2014) Mental health services in Australia: Medicaresubsidised mental health-related services. Available at: https://mhsa.aihw.gov.au/services/medicare/. 


\section{ATAPS for children}

Bassilios B, Nicholas A, Fletcher J, et al. (2014) Evaluating the Access to Allied Psychological Services (ATAPS) component of the Better Outcomes in Mental Health Care (BOiMHC) program. Special Report: An evaluation of the ATAPS Child Mental Health Service. Melbourne: Centre for Health Policy, Programs and Economics, The University of Melbourne.

Bassilios B, Nicholas A, Reifels L, et al. (2013) Evaluating the Access to Allied Psychological Services (ATAPS) program: Consolidated 10-year Report. Available at: https://atapsmds.com/site/assets/files/1016/ten_year_ataps_report_final_acc.pdf.

Bassilios B, Pirkis J, Fletcher J, et al. (2010) The complementarity of two major Australian primary mental health care initiatives. Australian and New Zealand Journal of Psychiatry 44: 9971004.

Bassilios B, Pirkis J, King K, et al. (2012a) Evaluation of an Australian primary care telephone cognitive behavioural therapy pilot. Australian Journal of Primary Health 20: 62-73.

Bassilios B, Reifels L and Pirkis J. (2012b) Enhanced primary mental health services in response to disaster. Psychiatric Services 63: 868-874.

Cesare LA. (2013) Outcomes Measurement Essential for Post-Reform Healthcare Success: It's Time for Our Field to Measure the Value of Our Work. If We Don't, Others Will Do It for Us. Behavioral healthcare 33.

Clement S, Schauman O, Graham T, et al. (2014) What is the impact of mental health-related stigma on help-seeking? A systematic review of quantitative and qualitative studies. Psychological Medicine: 1-17.

Department of Health. (2014) Primary Health Networks Grant Programme Guidelines, V1.1. Available at: http://www.health.gov.au/internet/main/publishing.nsf/Content/PHNProgram Guidelines.

Di Bona L, Saxon D, Barkham M, et al. (2014) Predictors of patient non-attendance at Improving Access to Psychological Therapy services demonstration sites. Journal of Affective Disorders. 


\section{ATAPS for children}

Harris M, Pirkis J, Burgess P, et al. (2010) Evaluation of the Better Access to Psychiatrists, Psychologists and GPs through the Medicare Benefits Schedule initiative - Component B: An analysis of Medicare Benefits Schedule (MBS) and Pharmaceutical Benefits Scheme (PBS) administrative data. FINAL REPORT. Melbourne: Centre for Health Policy, Programs and Economics, The University of Melbourne.

Hickie I and Groom G. (2002) Primary care-led mental health service reform: An outline of the Better Outcomes in Mental Health Care initiative. Australasian Psychiatry 10: 376-382.

Johnson SE, Lawrence D, Hafekost J, et al. (2016) Service use by Australian children for emotional and behavioural problems: Findings from the second Australian Child and Adolescent Survey of Mental Health and Wellbeing. Australian and New Zealand Journal of Psychiatry: 0004867415622562.

Kessler RC, Angermeyer M, Anthony JC, et al. (2007) Lifetime prevalence and age-of-onset distributions of mental disorders in the World Health Organization's World Mental Health Survey Initiative. World Psychiatry 6: 168-176.

King K, Bassilios B, Reifels L, et al. (2013) Suicide prevention: Evaluation of a pilot intervention in a primary care context. Journal of Mental Health 22: 439-448.

Lawrence D, Hafekost J, Johnson SE, et al. (2015) Key findings from the second Australian Child and Adolescent Survey of Mental Health and Wellbeing. Australian and New Zealand Journal of Psychiatry: 0004867415617836.

Morgan AJ, Reavley NJ and Jorm AF. (2014) Beliefs about mental disorder treatment and prognosis: comparison of health professionals with the Australian public. Australian and New Zealand Journal of Psychiatry 48: 442-451.

Morley B, Pirkis J, Naccarella L, et al. (2007) Improving access to and outcomes from mental health care in rural Australia. Australian Journal of Rural Health 15: 304-312.

National Mental Health Commission. (2014) The national review of mental health programmes and services summary. Sydney: NMHC. 


\section{ATAPS for children}

Pirkis J, Ftanou M, Williamson M, et al. (2011) Australia's Better Access initiative: an evaluation . . Australian and New Zealand Journal of Psychiatry 45: 726-739.

Reifels L, Bassilios B, King K, et al. (2013) Innovations in primary mental health care. Australian Health Review 37: 312-317.

Reifels L, Bassilios B, Spittal MJ, et al. (2015) Patterns and predictors of primary mental health service use following bushfire and flood disasters. Disaster Medicine and Public Health Preparedness.

Sawyer SM, Arney FM, Baghurst PA, et al. (2000) Child and Adolescent Component of the National Survey of Mental Health and Well-being: Mental health of young people in Australia. Canberra: Mental Health and Special Programs Branch, Commonwealth Department of Health and Aged Care.

Smith T, Linnemeyer R, Scalise D, et al. (2013) Barriers to Outpatient Mental Health Treatment for Children and Adolescents: Parental Perspectives. Journal of Family Psychotherapy 24: 73-92.

Wolpert M, Fugard AJB, Deighton J, et al. (2012) Routine outcomes monitoring as part of children and young people's Improving Access to Psychological Therapies (CYP IAPT) - improving care or unhelpful burden? Child and Adolescent Mental Health 17: 129-130. 
ATAPS for children

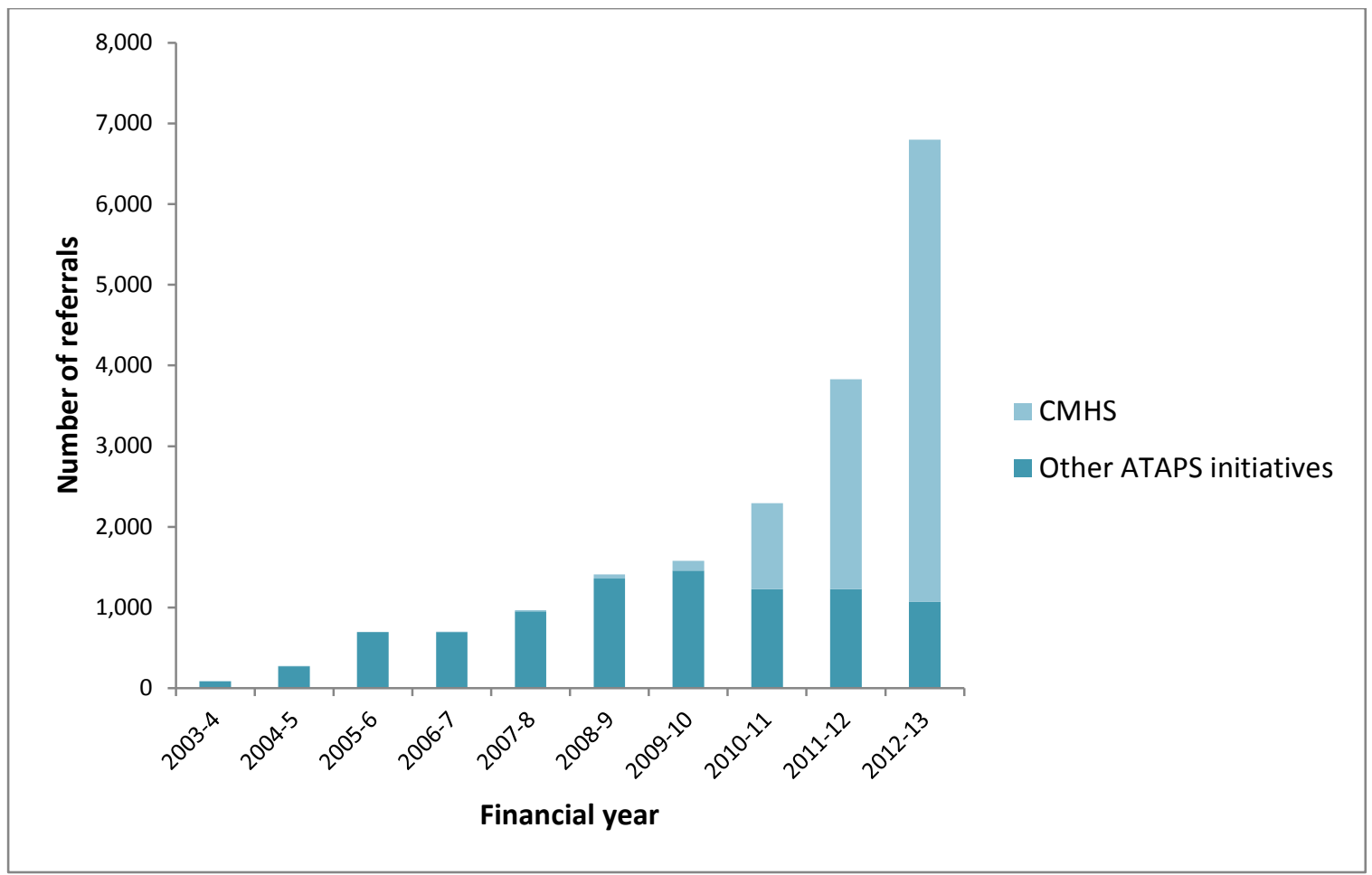

Figure 1. Number of referrals for children to ATAPS initiatives (July 2003 to June 2013), by financial year.

ATAPS, Access to Allied Psychological Services; CMHS, Child Mental Health Service 


\section{ATAPS for children}

Table 1. Simple correlations between predictor variables and rate of children referred to the CMHS, and regression coefficients $(B)$

\begin{tabular}{|c|c|c|c|c|c|c|}
\hline & \multicolumn{4}{|c|}{ Correlations } & \multicolumn{2}{|l|}{ Regression } \\
\hline Predictor & $\begin{array}{c}\text { Child } \\
\text { referral rate } \\
\text { per } 100 \\
\text { children in } \\
\text { Medicare } \\
\text { Local's } \\
\text { population } \\
\end{array}$ & 1 & 2 & 3 & $B(95 \% \mathrm{Cl})$ & $p$ \\
\hline $\begin{array}{l}\text { 1) Percent of children in Medicare Local's } \\
\text { population of children in two most } \\
\text { disadvantaged quintiles }\end{array}$ & .28 & & & & $.002(-.002-.006)$ & .306 \\
\hline $\begin{array}{l}\text { 2) Percent of children in Medicare Local's } \\
\text { population of children in regional and } \\
\text { remote locations }\end{array}$ & .19 & .56 & & & $.000(-.002-.002)$ & .827 \\
\hline $\begin{array}{l}\text { 3) Medicare Local's rate of ATAPS referrals } \\
\text { for consumers aged } 12+\text { years }^{a}\end{array}$ & .38 & .50 & .49 & & $.059(.006-.112)$ & .029 \\
\hline 4) Tranche & -.15 & .12 & .09 & .06 & $-.050(-.115-.015)$ & .130 \\
\hline
\end{tabular}


Table 2. Demographic and clinical characteristics of children referred to the CMHS (and all Australian children), and interventions delivered

\begin{tabular}{|c|c|c|c|}
\hline \multirow[b]{2}{*}{ Characteristic } & \multicolumn{2}{|c|}{ ATAPS } & \multirow{2}{*}{$\begin{array}{c}\begin{array}{c}\text { Australiar } \\
\text { children }^{f}\end{array} \\
\% \\
\end{array}$} \\
\hline & $\mathrm{n}$ & $\%$ & \\
\hline \multicolumn{4}{|l|}{ Gender $^{a}$} \\
\hline Female & 4,220 & 46.4 & 48.7 \\
\hline Male & 4,764 & 52.4 & 51.3 \\
\hline Missing & 106 & 1.2 & \\
\hline \multicolumn{4}{|l|}{ Aboriginal $^{\mathrm{a}}$} \\
\hline Yes & 395 & 4.3 & 4.1 \\
\hline No & 6,572 & 72.3 & 90.0 \\
\hline Unknown & 1,550 & 17.1 & $5.7^{8}$ \\
\hline Missing & 573 & 6.3 & \\
\hline \multicolumn{4}{|l|}{ Torres Strait Islander $^{\mathrm{a}}$} \\
\hline Yes & 102 & 1.1 & 0.45 \\
\hline No & 6,694 & 73.6 & 90.0 \\
\hline Unknown & 1,599 & 17.6 & $5.7^{\mathrm{g}}$ \\
\hline Missing & 695 & 7.6 & \\
\hline \multicolumn{4}{|l|}{ Language spoken at home ${ }^{a}$} \\
\hline English & 7,839 & 86.2 & $91.7^{\mathrm{h}}$ \\
\hline Other ${ }^{b}$ & 77 & 0.8 & $2.6^{\mathrm{i}}$ \\
\hline Unknown & 613 & 6.7 & $5.7^{\mathrm{g}}$ \\
\hline Missing & 562 & 6.2 & \\
\hline \multicolumn{4}{|l|}{ Low income } \\
\hline Yes & 5,705 & 59.5 & \\
\hline No & 964 & 10.1 & \\
\hline Unknown & 2,362 & 24.6 & \\
\hline Missing & 555 & 5.8 & \\
\hline \multicolumn{4}{|l|}{ Age group } \\
\hline $0-4$ & 542 & 5.7 & \\
\hline $5-9$ & 3,613 & 37.7 & \\
\hline $10-11$ & 2,006 & 20.9 & \\
\hline $12-15$ & 2,346 & 24.5 & \\
\hline $16+^{c}$ & 649 & 6.8 & \\
\hline Missing & 430 & 4.5 & \\
\hline \multirow[t]{2}{*}{ Mean age } & Mean & SD & \\
\hline & 9.5 & 3.1 & \\
\hline \multicolumn{4}{|l|}{ Remoteness area } \\
\hline Major Cities of Australia & 5,389 & 56.2 & 66.3 \\
\hline Inner Regional Australia & 2,366 & 24.7 & 20.7 \\
\hline Outer Regional Australia & 1,285 & 13.4 & 10.2 \\
\hline Remote Australia & 70 & 0.7 & 1.7 \\
\hline Very Remote Australia & 8 & 0.1 & 1.0 \\
\hline
\end{tabular}




\section{ATAPS for children}

\begin{tabular}{|c|c|c|c|}
\hline Unknown & 25 & 0.3 & $0.1^{\mathrm{j}}$ \\
\hline Missing & 443 & 4.6 & \\
\hline \multicolumn{4}{|l|}{ Previous psychiatric care } \\
\hline Yes & 2,272 & 23.7 & \\
\hline No & 4,519 & 47.1 & \\
\hline Unknown & 2,188 & 22.8 & \\
\hline Missing & 607 & 6.3 & \\
\hline \multicolumn{4}{|l|}{ Diagnosis $^{d}$} \\
\hline Alcohol and drug use disorders & 32 & 0.3 & \\
\hline Anxiety disorders & 3,252 & 33.9 & \\
\hline Enuresis & 7 & 0.1 & \\
\hline Conduct disorder & 26 & 0.3 & \\
\hline Depression & 1,722 & 18.0 & \\
\hline Dissociative (conversion) & 3 & 0.0 & \\
\hline Eating disorders & 6 & 0.1 & \\
\hline $\begin{array}{l}\text { Hyperkinetic (attention deficit) } \\
\text { Neurasthenia (chronic fatigue }\end{array}$ & 35 & 0.4 & \\
\hline syndrome) & 1 & 0.0 & \\
\hline Psychotic disorders & 28 & 0.3 & \\
\hline Sexual disorders & 2 & 0.0 & \\
\hline Sleep problems & 18 & 0.2 & \\
\hline Unexplained somatic disorders & 163 & 1.7 & \\
\hline Other diagnosis & 3,034 & 31.7 & \\
\hline No formal diagnosis & 284 & 3.0 & \\
\hline Unknown & 528 & 5.5 & \\
\hline Missing & 2,412 & 25.2 & \\
\hline \multicolumn{4}{|l|}{ Interventions ${ }^{e}$} \\
\hline Diagnostic assessment & 7,848 & 21.9 & \\
\hline Psycho-education & 9,445 & 26.3 & \\
\hline CBT-Behavioural & 14,211 & 39.6 & \\
\hline CBT-Cognitive & 14,016 & 39.1 & \\
\hline CBT-Relaxation & 5,743 & 16.0 & \\
\hline CBT-Skills training & 8,896 & 24.8 & \\
\hline Interpersonal therapy & 7,040 & 19.6 & \\
\hline Narrative therapy & 778 & 2.2 & \\
\hline Family-based intervention & 2,037 & 5.7 & \\
\hline $\begin{array}{l}\text { Parent training in behaviour } \\
\text { management }\end{array}$ & 2,598 & 7.2 & \\
\hline Attachment & 196 & 0.5 & \\
\hline Parent-child interaction therapy & 102 & 0.3 & \\
\hline Other CBT strategies & 574 & 1.6 & \\
\hline Other strategies & 1,914 & 5.3 & \\
\hline Missing & 2,851 & 8.0 & \\
\hline
\end{tabular}

CMHS, Child Mental Health Service; CBT, cognitive behavioural therapy.

a Individuals may be referred multiple times; the denominator 9090 is used for stable characteristics of unique persons. Individuals may be referred mulliple times, the denominator 9009 is

${ }^{b}$ Other languages in order of decreasing frequency include Arabic, Mandarin, Cantonese, Greek, Italian and Vietnamese.

${ }^{\mathrm{c}} \mathrm{A}$ small proportion of referrals appear to be for children aged over 15 years, and this may or may not reflect errors in dat entry.

Multiple diagnoses permissible per consumer.

${ }^{e}$ Multiple interventions permissible per consumer; denominator is attended sessions $(35,854)$. 


\section{ATAPS for children}

fData derived from 2006 Census using TableBuilder (Australian Bureau of Statistics, 2007), at which time there were $4,215,700$ children aged $0-15$ years.

${ }^{\mathrm{g}}$ Not stated.

${ }^{\mathrm{h}}$ Includes $81.5 \%$ English-speaking only and $10.2 \%$ speaking English very well or well in addition to another language.

Includes speaks another language and no/not well English.

jNo usual address. 


\section{University Library}

\section{- M M N E R VA A gateway to Melbourne's research publications}

Minerva Access is the Institutional Repository of The University of Melbourne

Author/s:

Bassilios, B;Nicholas, A;Reifels, L;King, K;Spittal, MJ;Fletcher, J;Pirkis, J

Title:

Improving access to primary mental health care for Australian children

Date:

2016-11-01

Citation:

Bassilios, B., Nicholas, A., Reifels, L., King, K., Spittal, M. J., Fletcher, J. \& Pirkis, J. (2016). Improving access to primary mental health care for Australian children. AUSTRALIAN AND NEW ZEALAND JOURNAL OF PSYCHIATRY, 50 (11), pp.1074-1084. https:// doi.org/10.1177/0004867416671412.

Persistent Link:

http://hdl.handle.net/11343/122840 